Library Acquisitions: Practice and Theory, (1990), v.14, iss.2,pp.209-210.

ISSN: 0364-6408

http://www.sciencedirect.com/science/journal/03646408/14/2

http://www.sciencedirect.com/science/article/pii/0364640890900642

http://dx.doi.org/10.1016/0364-6408(90)90064-2

(C)1990 Pergamon Press

ALA MIDWINTER CONFERENCE 1990

\title{
HIGHLIGHTS OF THE ACQUISITIONS LIBRARIANS/VENDORS OF LIBRARY MATERIALS DISCUSSION GROUP
}

\section{CAROL PITTS HAWKS}

More than 150 librarians, vendors, and publishers gathered on Tuesday, January 9, 1990, at Chicago's Palmer House to hear presentations on "A National Publication Pattern Database."

Bonnie Postlethwaite (The Faxon Co.) led off the morning by presenting her concept of a national database for serials publication patterns. Not only is it very expensive to implement serials check-in automation, but ongoing matintenance is equally time-consuming and expensive. A great deal of wasteful duplication of effort and redundancy could be eliminated with a shared database. A single serial can have multiple publication patterns with each pattern associated with a group of serial issues sharing the same pattern.

The database would have a number of uses for acquisitions. For example, it would be easier to determine which issue to begin a new subscription or to cancel an existing subscription. Orders could be placed more quickly, and serials check-in would be faster and more accurate. Claiming would also be more accurate, and premature claims could be reduced or eliminated. The flow of information between all parties could be in a standard form. The accuracy of binding predictions would also be enhanced.

Bonnie identified four issues involved in the creation of such a database:

1. Timeliness of information. The verification process used in cataloging databases would not be acceptable. The currency of information would take precedence over verification.

2. Quality control. The cooperation of publishers is needed but the primary burden will fall on libraries. Who will be the authority?

3. Storage capacity. The volume of material needed for the database is quite extensive. Some of this would need to be streamlined as much as possible to keep the cost viable.

4. Data distribution. The ability to access and transfer data would have to occur in real time to be valuable.

Marilyn Norstedt (Virginia Tech) presented her thoughts on the database from her perspective as a librarian. Marilyn likened her comments to "preaching to the converted." It is imperative that such a venture be supported by the bibliographic utilities, systems vendors, and subscription agents as well as librarians.

Because individual libraries are already spending a great deal of time maintaining this information locally, the maintenance of a national database would be little additional work, 
provided the information did not have to be updated twice. Thus, maintenance is not the issue; the real issue is the creation/development of the database. Bonnie's suggestion of a CONSER-type administration is the most suitable.

Marilyn closed with thanks to Bonnie for getting this effort underway. Now, more than a concept in hand is needed. Since there is much visible support and little disagreement with the idea, it is time for action. An ALCTS task force should be formed and charged with developing this proposal. Its membership should include individuals with a very practical yet knowledgeable approach.

Rebecca Lenzini (Carl Systems, Inc.) began her presentation with her personal history of being in all camps - librarian, materials vendor, and systems vendor. The systems vendor has two roles: to facilitate access to information and to make things easier for libraries. No one can deny that the concept of a national pattern database is basic "apple pie and motherhood," but there are many logistics to be worked out. Although the concept is very similar to the concept behind OCLC, the cost justification will be a harder sale. Finally, the time to develop such a database is now when many vendors are redesigning their serials control systems.

The session closed with some active discussion followed by a call to action. People interested in working on the issue are encouraged to contact Bonnie Postlethwaite, The Faxon Co., 15 Southwest Park, Westwood, MA 02090. 